\title{
Probing inside fruit slices during convective drying by quantitative neutron imaging
}

Thijs Defraeye ${ }^{\mathrm{a}, \mathrm{b}, \mathrm{c}}$, Bart Nicolaî ${ }^{\mathrm{c}, \mathrm{d}}$, David Mannes ${ }^{\mathrm{e}}$, Wondwosen Aregawi ${ }^{\mathrm{c}}$, Pieter Verboven ${ }^{\mathrm{c}}$, Dominique Derome ${ }^{\mathrm{a}}$

${ }^{a}$ Laboratory for Multiscale Studies in Building Physics, Swiss Federal Laboratories for Materials Testing and Research (Empa), Überlandstrasse 129, 8600 Dübendorf, Switzerland

${ }^{b}$ Chair of Building Physics, Swiss Federal Institute of Technology Zurich (ETHZ), Stefano-Franscini-Platz 5, 8093 Zürich, Switzerland

${ }^{c}$ MeBioS, Department of Biosystems, University of Leuven, Willem de Croylaan 42, 3001 Heverlee, Belgium

${ }^{d}$ VCBT, Flanders Centre of Postharvest Technology, Willem de Croylaan 42, 3001 Heverlee, Belgium

e Paul Scherrer Institute (PSI), 5234 Villigen, Switzerland

\section{* Corresponding author}

- E-mail defraeye@arch.ethz.ch

- Tel. $\quad+41(0) 587654790$

- Fax. $\quad+41446331041$

\begin{abstract}
Quantitative neutron imaging was applied for the dynamic monitoring of the internal moisture distribution of fruit slices during convective drying in a drying tunnel. The impact of several process conditions was evaluated, including airflow temperature, air speed and incident radiation. This technique also unveiled that anisotropic shrinkage was caused, in part, by spatially heterogeneous dehydration, as induced by the presence of the peel. Neutron imaging provided unique graphical and quantitative insights on how the internal water distribution evolved. Thereby, this imaging technique has large potential to complement conventional techniques for monitoring, controlling and optimising drying processes of complex biomaterials, or to generate high-resolution validation data for numerical simulations.
\end{abstract}

Keywords: non-destructive imaging, apple, convective, drying, tunnel, dehydration 


\section{Introduction}

Drying is one of the most important thermal processing operations for preserving fresh fruits and vegetables (Dev and Raghavan, 2012). The resulting extended shelf life and prolonged storage capability guarantee off-season availability of this source of nutrition and also help in reducing food waste. These aspects are critical in developing countries, which often rely on solar energy to dry fruit due to the limited access to conventional energy sources. In developed countries, dried fruits are gaining popularity as healthy snacks, for example apple chips or fruit leathers. Efforts towards enhancing drying processes of such products and the resulting product quality are therefore on the rise (Defraeye, 2014). Both lowtech solutions for rural application, such as solar-assisted dryers, as well as high-tech industrial implementations are targeted. The latter mainly aim at reducing energy consumption and delivering a uniform product quality, which is extremely challenging for complex biomaterials such as fruits.

Next to the recent computational modelling efforts on fruit and vegetable drying (Halder and Datta, 2012; Marra et al., 2010), a large amount of experimental work was performed (Santacatalina et al., 2014; Sturm et al., 2012). Most of these experiments however target the overall drying kinetics and final product quality but do not probe the moisture transport inside the fruit during drying. Internal water transport is however decisive for the moisture content and its distribution within the fruit after drying, the product's final microstructure, the sorption and rehydration behaviour, and the degree of case hardening. Opportunely, non-destructive imaging provides ways of dynamically monitoring water distribution during drying (Nicolaï et al., 2014).

The most commonly-used imaging techniques that have been applied for fruit drying are nuclear magnetic resonance (NMR, (Van As and van Duynhoven, 2013)), X-ray radiography/tomography (Léonard et al., 2008) and neutron radiography/tomography (Aregawi et al., 2013; Defraeye et al., 2012a). They differ with respect to their spatial and temporal resolution, their capability to detect water qualitatively (dynamic range, i.e. the number of contrast levels) and quantitatively (absolute water content), their accessibility and their ease of use (Defraeye et al., 2012a). Neutron imaging has some particular advantages. It provides a very high dynamic range since the neutron beam is attenuated strongly by hydrogen, thus water. In addition, a straightforward correction procedure exists (Hassanein et al., 2005), by which accurate water content distributions can easily be obtained from the neutron radiographs, which is so-called quantitative neutron imaging. Combined with its spatial and temporal resolution (typically $\sim 10^{1}-10^{2} \mu \mathrm{m}$ and $\sim 10 \mathrm{~s}$ for a radiograph), this technique is particularly suitable for monitoring and analysing internal water transport and water loss during drying of whole, fresh-cut fruit slices in a non-intrusive way. Only a few studies have been reported for this application, but they had a rather limited quantitative appraisal (Balasko et al., 2002) or aimed at evaluating the accuracy of the technique for academic cases, which had limited similarity with actual convective drying applications (Aregawi et al., 2013; Defraeye et al., 2012a). A downside of neutron imaging is the limited number of dedicated beamlines available, but the situation is rapidly improving (Lehmann and Ridikas, 2014).

This study probes the water distribution changes in apple fruit slices during forced convective drying by quantitative neutron imaging. The specific aim is to take new steps in this field, namely by considering a realistic turbulent airflow 
field around the fruit in a drying tunnel, and by targeting the impact of several process conditions (airflow temperature, air speed and incident radiation), and the presence of the fruit peel.

\section{Materials and methods}

The imaging facilities of the NEutron Transmission RAdiography beamline (NEUTRA) at the Paul Scherrer Institute (PSI, Villigen, Switzerland) were used for detailed visualization and quantification of transient water transport in apple fruit tissue. The experimental characteristics for imaging are: a CCD camera with $2048 \times 2048$ pixels, a pixel resolution of 100 $\mu \mathrm{m}$ and an exposure time per radiograph of $13 \mathrm{~s}$.

An open-circuit, custom-built, aluminium wind tunnel (Lal et al., n.d.) was used to subject fruit samples to controlled airflow conditions while imaging their internal water content distribution with neutron radiography. The channel test section was $316 \times 50 \times 105 \mathrm{~mm}$ (length $\mathrm{x}$ height $x$ width, $x-y-z$ ). Two airflow rates were evaluated in this study, leading to average air speeds in the test section of 1.1 and $2.6 \mathrm{~m} \mathrm{~s}^{-1}\left(U_{\text {avg }}\right)$. These speeds correspond to Reynolds numbers $(R e)$ of 3700 to 9000 (based on $U_{\text {avg }}$ and channel height $H$ ), which implies turbulent flow. The temperature of the approach flow $\left(T_{A F}\right)$ was actively controlled, which thereby also affected the relative humidity $\left(R H_{A F}\right.$, not controlled but rather low due to the specific environmental conditions in the neutron facility). Several experiments were performed, of which the details are given in Table 1. In some experiments, irradiation onto the fruit surface was added by means of a lamp (Osram "Ultra-Vitalux", $300 \mathrm{~W}$ ). This lamp was placed at an oblique angle above the transparent, glass test section roof $\left(45^{\circ}\right)$, at $30 \mathrm{~cm}$ distance from the fruit sample). For one experiment (Ex7), only natural convection was induced, driven by irradiation, instead of forced convection.

Apple fruits (cv. Braeburn) were used. Half-circular apple slices of about $1 \mathrm{~cm}$ thick were cut along the centre axis of the fruit (axis from petiole to crown, see Figure 1). With one sample (Ex4), the peel was removed. Each sample was suspended on two needles in the centre $(x-y-z)$ of the test section, after which the drying process was started. Each experiment took around 8-10 h, during which neutron radiographs were acquired every minute.

The initial mass $\left(m_{i n i}\right)$ of each sample and its mass at the end of the experiment ( $\left.m_{\text {end }}\right)$ were measured gravimetrically, from which the total sample water loss was determined $\left(\Delta m_{\text {grav }}=m_{\text {ini }}-m_{\text {end }}\right)$. The initial water content $\left(w_{\text {ini }}\right)$ was determined as the ratio of the total amount of water in the fruit sample (difference of initial mass $\left(m_{\text {ini }}\right)$ and dry mass after oven drying the sample $\left.\left(m_{d r y}\right)\right)$ to the initial sample volume (see Table 1$)$. This sample volume was estimated from the initial sample thickness $\left(d_{i n i}\right)$ and the frontal, cross-sectional area in the initial neutron radiograph $\left(A_{f, i n i}\right.$, see Figure 1). Note that the samples were not fully dry, i.e. in equilibrium with the drying air, at the end of the experiments. This means that still an amount of moisture is present in the samples.

The neutron radiographs were corrected to obtain quantitative estimates of the water content distribution inside the sample. The applied correction procedure was developed by (Hassanein et al., 2005) and is described in detail in 
(Defraeye et al., 2012a) for fruit drying. Due to the thin aluminium walls of the test section and their transparency for neutrons, only the fruit attenuated the neutron beam. This correction procedure assumes that beam attenuation is only caused by water inside the fruit, and does not account for attenuation by the fruit tissue. This assumption was shown to give a satisfactory accuracy (Defraeye et al., 2012a) since fruits are mainly composed out of water. Note that when differences in moisture content between two images are considered, e.g. when comparing the mass loss between the initial state and a partially dried sample after a few hours, the fruit tissue contribution is cancelled out as it is present in all images. These corrections resulted in radiograph images which directly provide the water distribution for each pixel $\left(\mathrm{g} \mathrm{cm}^{-2}\right)$, out of which the total water loss of the sample could be determined over time $\left(\Delta m_{\text {neutr }}(t)\right)$.

\section{Results and discussion}

The moisture distribution inside the fruit at different times during the drying process is illustrated in Figure 1 for four experiments: forced convection with peel, forced convection without peel, forced convective airflow combined with additional irradiation, and radiation-driven natural convection. The moisture distribution is represented dimensionless by scaling the corrected quantitative neutron radiographs (in $\mathrm{kg} \mathrm{m}^{-2}$ ), namely by dividing by an average slice thickness ( 1 $\mathrm{cm})$ and by an average moisture content of fresh apple fruit $\left(666 \mathrm{~kg} \mathrm{~m}^{-3}\right)$, and scaling these quantities to standard units. Since the same scaling factor is used for all experiments, differences in initial moisture content are visible in Figure 1. In addition, the mass loss from each sample over time $\left(\Delta m_{\text {neutr }}(t)\right)$ was determined from the corrected neutron radiographs (Figure 2 and Table 1). This mass loss (in g) was scaled with a surface area (in $\mathrm{cm}^{-2}$ ) since the size of the samples differed, thus also the surface area exposed for vapour exchange. Scaling was done by dividing the mass loss with two times the initial frontal area $\left(A_{f, i n i}\right)$. Such scaling leads to mass loss per unit surface area $\left(\mathrm{g} \mathrm{cm}^{-2}\right)$ over time, which allows better comparison between different experiments. The differences found between the mass loss from neutron imaging and that from gravimetrical measurements (Table 1) are comparable to those of (Defraeye et al., 2012a). These were around $20-30 \%$ and also possible reasons for this mismatch are given.

The images from Figure 1 provide unique information on moisture distribution and gradients. The peel has a distinct impact on the dehydration and deformation behaviour. Without a peel, the deformation and dehydration is quasi isotropic in $x$ and $y$ directions. With the peel however, the fruit curls as the lower edge shrinks. This phenomenon is, in part, caused by the extra mechanical stability that the thin peel provides, since it is stiffer than the tissue. From the neutron radiographs, another contribution to the anisotropic deformation is suggested. In the vicinity of the peel, the moisture content seems to remain slightly higher than in the rest of the tissue, as the peel forms a moisture barrier. For fruit, the deformation is linearly related to the volumetric water loss during a large part of the drying process (Mayor and Sereno, 2004). Thereby, the deformation will be smaller just below the peel. As such, spatially heterogeneous dehydration (in the $x-y$ plane) induces a differential (anisotropic) shrinkage pattern. 
From Figure 2a, increasing the air speed (with a factor 2.3) did not induce a large increase in the drying rate (compare red with blue curves). The most probable reason is that the fruit goes relatively quickly to the second (falling) drying rate period, as many fruits do (Mcminn and Magee, 1999), so with a rather short constant drying rate period. In this case, the resistance of the boundary layer to moisture removal, typically characterized by the convective mass transfer coefficient, does not affect the mass transfer rate significantly (Defraeye et al., 2012b). An increase in approach flow temperature however had a larger impact, which is attributed to the lower induced relative humidity of the approach flow and the higher surface temperature and saturation vapour pressure at the surface.

Clear differences are present between forced convective drying with irradiation versus solely natural convective drying. The natural convective case dries slow at the start, but seems to exhibit a rather long first (constant) drying rate period, as suggested by the constant slope in the mass loss curve. This leads to a larger mass loss (rate) at the end of the experiment, and a dry sample (Figure 1). For the forced convective case, the airflow will remove some of the irradiation heat supplied to the surface. This cooling of the surface can negatively affect the drying rate due to the lower vapour pressure. However, to gain better insights in this matter, knowledge of the heat and mass budgets at the surface, in the airflow and inside the material is critical. To this end, more complete experiments could be devised, in which neutron imaging can take care of the moisture distribution monitoring. In addition, infrared thermography or thermocouples should be used to measure surface and internal temperatures, and where fruit mass loss is monitored gravimetrically. Also computational modelling can provide essential complementary information.

\section{Conclusions}

This study showed that quantitative neutron imaging is successful in dynamically monitoring the internal moisture distribution inside fruits during various convective drying processes in a drying tunnel. This technique was used to identify the impact of several process conditions (air speed, approach flow temperature, incident radiation). Anisotropic shrinkage was found to be related, in part, to spatially heterogeneous spatial dehydration, as induced by the presence of the peel. For a better understanding and control of drying processes, future experiments need to monitor simultaneously multiple process parameters and product quality aspects. In this context, neutron imaging can provide a unique added value to conventional techniques. In addition, it is the perfect tool to generate advanced validation datasets for numerical multiphysics models on dehydration.

\section{Acknowledgements}

We acknowledge the support of the World Food System Center (WFSC) of ETH Zürich (www.worldfoodsystem.ethz.ch) and the support of the Swiss National Science Foundation SNSF (project 200021_160047). 


\section{References}

Aregawi, W., Defraeye, T., Saneinejad, S., Vontobel, P., Lehmann, E., Carmeliet, J., Derome, D., Verboven, P., Nicolai, B., 2013. Dehydration of apple tissue: Intercomparison of neutron tomography with numerical modelling. Int. J. Heat Mass Transf. 67, 173-182.

Balasko, M., Korosi, F., Farkas, I., 2002. Applying dynamic neutron radiography in in-situ monitoring of the drying processes of apple. Dev. Chem. Eng. Miner. Process. 10, 247-260.

Defraeye, T., 2014. Advanced computational modelling for drying processes - a review. Appl. Energy 131, 323-344.

Defraeye, T., Aregawi, W., Saneinejad, S., Vontobel, P., Lehmann, E., Carmeliet, J., Verboven, P., Derome, D., Nicolai, B., 2012a. Novel application of neutron radiography to forced convective drying of fruit tissue. Food Bioprocess Technol. 6, 3353-3367.

Defraeye, T., Blocken, B., Carmeliet, J., 2012b. Analysis of convective heat and mass transfer coefficients for convective drying of a porous flat plate by conjugate modelling. Int. J. Heat Mass Transf. 55, 112-124.

Dev, S.R.S., Raghavan, V.G.S., 2012. Advancements in drying techniques for food, fiber, and fuel. Dry. Technol. 30, 11471159.

Halder, A., Datta, A.K., 2012. Surface heat and mass transfer coefficients for multiphase porous media transport models with rapid evaporation. Food Bioprod. Process. 90, 475-490.

Hassanein, R., Lehmann, E., Vontobel, P., 2005. Methods of scattering corrections for quantitative neutron radiography. Nucl. Instruments Methods Phys. Res. Sect. A Accel. Spectrometers, Detect. Assoc. Equip. 542, 353-360.

Lal, S., Poulikakos, L.D., Jerjen, I., Vontobel, P., Partl, M.N., Carmeliet, J., Derome, D., n.d. Investigation of gravity-driven drainage and forced convective drying in macroporous media using neutron radiography. submitted.

Lehmann, E.H., Ridikas, D., 2014. Status of neutron imaging - activities in a worldwide context, in: 10th World Conference on Neutron Radiography.

Léonard, A., Blacher, S., Nimmol, C., Devahastin, S., 2008. Effect of far-infrared radiation assisted drying on microstructure of banana slices: An illustrative use of X-ray microtomography in microstructural evaluation of a food product. J. Food Eng. 85, 154-162.

Marra, F., De Bonis, M. V., Ruocco, G., 2010. Combined microwaves and convection heating: A conjugate approach. J. Food Eng. 97, 31-39.

Mayor, L., Sereno, A.M., 2004. Modelling shrinkage during convective drying of food materials: a review. J. Food Eng. 61, 373-386.

Mcminn, W.A.M., Magee, T.R.A., 1999. Principles, methods and applications of the convective drying of foodstuffs. Food Bioprod. Process. 77, 175-193.

Nicolaï, B.M., Defraeye, T., De Ketelaere, B., Herremans, E., Hertog, M.L.A.T.M., Saeys, W., Torricelli, A., Vandendriessche, T., Verboven, P., 2014. Nondestructive measurement of fruit and vegetable quality. Annu. Rev. Food Sci. Technol. 5, 285-312.

Santacatalina, J. V., Rodríguez, O., Simal, S., Cárcel, J. a., Mulet, a., García-Pérez, J. V., 2014. Ultrasonically enhanced lowtemperature drying of apple: Influence on drying kinetics and antioxidant potential. J. Food Eng. 138, 35-44. 
Sturm, B., Hofacker, W.C., Hensel, O., 2012. Optimizing the Drying Parameters for Hot-Air-Dried Apples. Dry. Technol. $30,1570-1582$.

Van As, H., van Duynhoven, J., 2013. MRI of plants and foods. J. Magn. Reson. 229, 25-34. 


\section{Tables}

Table 1. Process conditions, characteristics of apple slice samples and measurement results from neutron imaging for the different drying experiments.

\begin{tabular}{|c|c|c|c|c|c|c|c|}
\hline Exp. number & Ex1 & Ex2 & Ex3 & Ex4 & Ex5 & Ex6 & Ex7 \\
\hline Exp. name & Thigh_Ulow & Tlow_Ulow & Thigh_Uhigh & Thigh_Uhigh_noPeel & Tlow_Uhigh_Rad & Tlow_Ulow_Rad & NC_Rad \\
\hline \multicolumn{8}{|l|}{ PROCESS CONDITIONS } \\
\hline AF temperature $T_{A F}\left[{ }^{\circ} \mathrm{C}\right]$ & 39 (high) & 26 (low) & 35 (high) & 38 (high) & 26 (low) & 26 (low) & n.a. \\
\hline AF relative humidity $R H_{A F}[\%]$ & $12 \%$ & $23 \%$ & $14 \%$ & $12 \%$ & $23 \%$ & $23 \%$ & n.a. \\
\hline $\mathrm{AF}$ air speed $U_{\text {avg }}\left[\mathrm{m} \mathrm{s}^{-1}\right]$ & 1.2 (low) & 1.2 (low) & 2.7 (high) & 2.7 (high) & 2.6 (high) & 1.1 (low) & n.a. \\
\hline Additional incident radiation & No rad. & No rad. & No rad. & No rad. & Rad. & Rad. & Rad. \\
\hline Peel/no peel & Peel & Peel & Peel & No peel & Peel & Peel & Peel \\
\hline Duration experiment [h] & 7.1 & 8.2 & 10.1 & 10.0 & 10.1 & 10.0 & 10.0 \\
\hline \multicolumn{8}{|l|}{ SAMPLE CHARACTERISTICS } \\
\hline Initial sample thickness $d_{i n i}[\mathrm{~mm}]$ & 9.0 & 9.5 & 9.2 & 10.5 & 10.2 & 10.7 & 8.0 \\
\hline Initial frontal area $A_{f, i n i}\left[\mathrm{~cm}^{2}\right]$ & 20.0 & 16.7 & 17.0 & 15.8 & 18.3 & 18.0 & 17.7 \\
\hline Initial water content $w_{i n i}\left[\mathrm{~kg} \mathrm{~m}^{-3}\right]$ & 717 & 679 & 701 & 632 & 644 & 634 & 698 \\
\hline \multicolumn{8}{|l|}{ MEASUREMENTS } \\
\hline Mass loss, gravimetrical $\Delta m_{\text {grav }}[\mathrm{g}]$ & 9.3 & 6.1 & 9.2 & 9.8 & 9.7 & 9.3 & 9.7 \\
\hline Mass loss, neutron $\Delta m_{\text {neutr }}[\mathrm{g}]$ & 7.7 & 4.7 & 7.4 & 7.9 & 7.5 & 6.9 & 7.9 \\
\hline Difference in mass loss $\left(\Delta m_{\text {grav }}-\right.$ & $18 \%$ & $23 \%$ & $19 \%$ & $20 \%$ & $23 \%$ & $26 \%$ & $18 \%$ \\
\hline$\left.\Delta m_{\text {neutr }}\right) / \Delta m_{\text {grav }}[\%]$ & & & & & & & \\
\hline
\end{tabular}


Figures

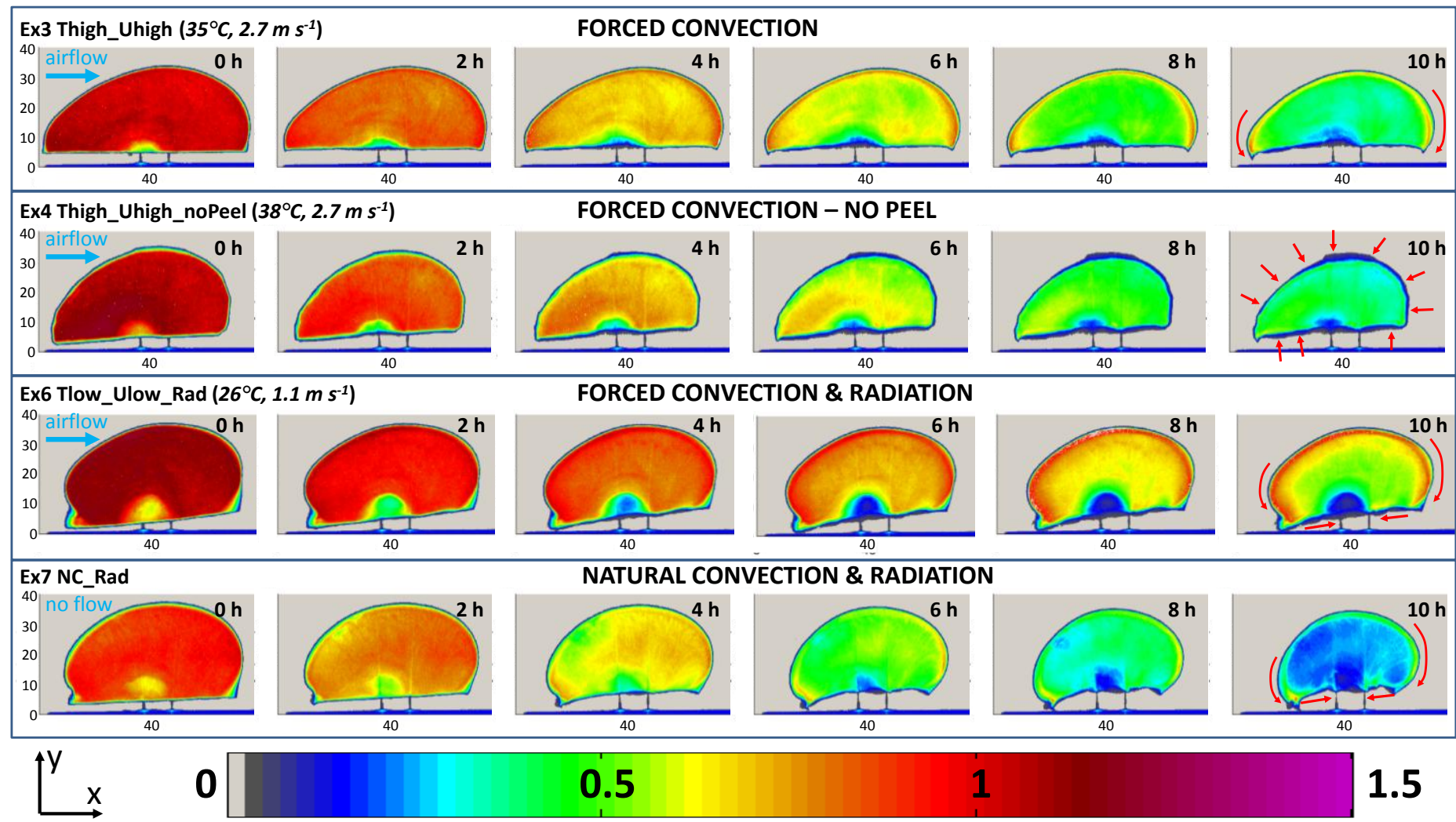

Figure 1. Internal distributions of scaled water content for apple fruit slices from neutron radiographs at different times for four different experiments. The same scaling factor is used for all images. The red arrows illustrate the deformation trend at the end of the drying process. Dimensions are in millimetres. 

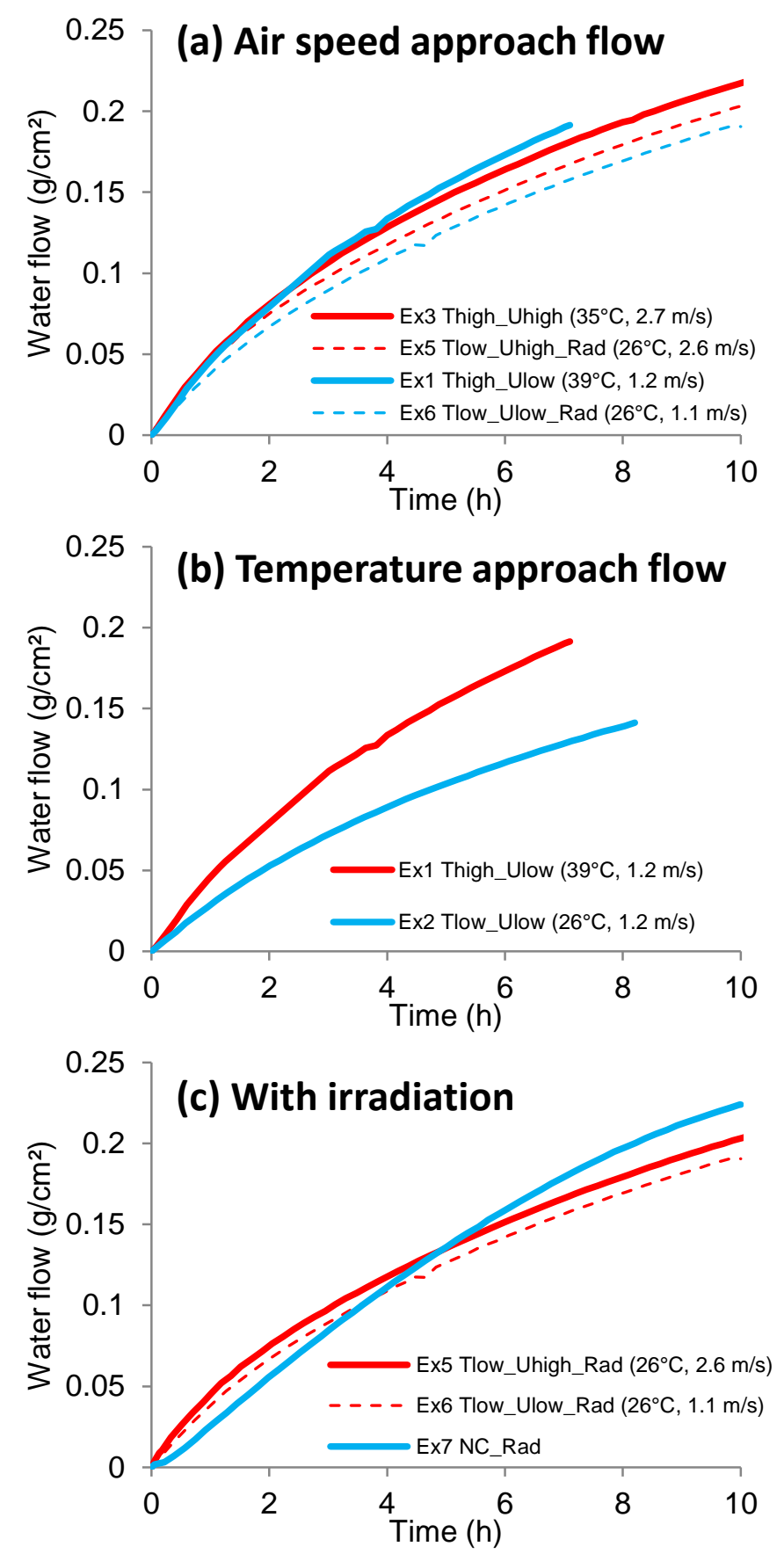

Figure 2. Water loss rate $\left(\mathrm{g} \mathrm{cm}^{-2}\right)$ from fruit samples during drying as a function of time from neutron radiographs for: (a) different approach flow speeds; (b) different approach flow temperatures; (c) with irradiation, with or without forced airflow. 